\title{
INCOME INEQUALITY OF HOUSEHOLDS IN POLAND: A SUBGROUP DECOMPOSITION OF GENERALIZED ENTROPY MEASURES
}

\author{
Joanna Muszyńska \\ Nicolaus Copernicus University in Torun, Torun, Poland \\ e-mail: Joanna.Muszynska@umk.pl
}

ORCID: 0000-0002-9436-4336

\section{Ewa Wędrowska}

Nicolaus Copernicus University in Torun, Torun, Poland e-mail: Ewa.Wedrowska@umk.pl

ORCID: 0000-0003-3902-0896

(C) 2018 Joanna Muszyńska, Ewa Wędrowska

This is an open access article distributed under the Creative Commons Attribution-NonCommercial-NoDerivs license (http://creativecommons.org/licenses/by-nc-nd/3.0/)

DOI: 10.15611/eada.2018.4.03

JEL Classification: D63, D31, C10

\begin{abstract}
A formula of measures applied to assess the level of income inequality results from the intellectual basis on which this approach is founded. Our paper focuses on Generalized Entropy measures. The aim of our paper is two-fold. Firstly, it aims at presenting GE measures and discussing their properties, especially the property of additive decomposition. Secondly, the empirical aim is to assess the level of income inequality in Poland and to indicate its main determinants. In the study we use microdata obtained from EU-SILC that cover information about incomes received by individual household members in 2016. Five factors are chosen as the possible drivers of income inequality. The study proves the characteristics related to human capital are the most influential factors of income variability between households. The characteristics describing the composition of the household contribute to the overall level of inequality to a smaller extent.
\end{abstract}

Keywords: income inequality, General Entropy measures, decomposition.

\section{Introduction}

There is a wide range of measures that can be applied to assess the level of income inequality. Their formula results from the intellectual basis on which this approach is founded. The choice of the appropriate measure does not depend only on the researcher's will, but is also related to the principles concerning the conceptual, methodological and technical qualities of the measures. While in many empirical 
works and public statistics the Gini coefficient is the most popular measure of income inequality, our paper focuses on Generalized Entropy measures. The aim of the paper is two-fold. Firstly, to present GE measures and discuss their properties, especially the property of additive decomposition, in order to demonstrate their usability in practical work. Secondly, the empirical aim is to estimate the level of income inequality in Poland and to examine the relationship between income inequality and household characteristics that can be a possible source of inequality.

The study is based on microdata obtained from the European Union Statistics on Income and Living Conditions (EU-SILC) under the project "Income and inequality of income of European households - RPP 162/2018-EU-SILC". The data cover information about incomes attained by individual members of the Polish households in 2016. GE measures are estimated based on the equivalised household disposable income per household member with the use of personal cross-sectional weights.

The paper is structured as follows. The next section presents the intellectual basis of Generalized Entropy measures. In Section 3 we focus on the properties of the measures and discuss the decomposition techniques based on the axiomatic approach. The empirical analysis is presented in Section 4. The last section offers our concluding remarks.

\section{Generalized Entropy Measures}

Cowell [1980], Cowell and Kuga [1981] and Shorrocks [1980; 1984] originated the Generalised Entropy (GE) class of inequality indices based on the idea of divergence between probability distributions derived from information theory. However, Theil [1967] was a pioneer of using the concepts defined in the theory of information in the study of inequality. Theil added intellectual basis of his own and argued that the concept of entropy provides a useful device for inequality measurement.

Statistical entropy as a basic concept in information theory, measuring the average missing information on a random source was introduced by Shannon. The entropy concept is the expected information in the distribution. For the discrete probability distribution $P(X)=\left\{p_{1}, p_{2}, \ldots, p_{n}\right\}, \sum_{i=1}^{n} p_{i}=1, \wedge_{i=1, \ldots, n} 0 \leq p_{i} \leq 1$, of $n$ possible states Shannon's entropy is defined as follows:

$$
H(X)=-\sum_{i=0}^{n} p_{i} \ln p_{i}=\sum_{i=0}^{n} p_{i} \ln \frac{1}{p_{i}} .
$$

Shannon's entropy is treated as the measure of uncertainty and it describes the 'degree of disorder'. H(X) given by formula (1) satisfies the properties specified also in the works of Przybyszewski, Wędrowska [2005] and Lesne [2014]:

1) It is a non-negative value, $H(X) \geq 0$,

2 ) it assumes the value of 0 , when one of the probability values $p_{i}=1$ and $p_{j}=0$ for $j \neq i(i, j=1, \ldots, n)$,

$3)$ it satisfies the property of symmetry: $H\left(p_{1}, p_{2}, \ldots, p_{n}\right)=H\left(p_{(1)}, p_{(2)}, \ldots, p_{(n)}\right)$, 
4) it assumes the highest value equal to $H(X)=\ln (n)$, when all the probability values are equal for $j=1, \ldots, n$ :

5) $p_{1}=p_{2}=\ldots=p_{n}=\frac{1}{n^{\prime}}$

6) it is concave: $\bigwedge_{i=1, \ldots, n} \frac{\delta^{2}}{\delta p_{i}{ }^{2}} H(X) \leq 0$.

Entropy is not a feature of the random variable itself, but it depends only on the set of its probability values. $H(X)$ is maximal, equal to $\ln (n)$, for a uniform distribution, so if there is the greatest uncertainty as to which an event will occur. With this in mind, Theil assumed that income inequality can be defined as the subtraction of the actual entropy of the income distribution from the maximum possible value of this entropy of the equal distribution $\left(Y_{e}\right)$. Based on the concept of information theory, the Theil index aims to quantify the level of disorder within a distribution of income. Theil's measure, like measures based on the Lorenz function, assesses the level of inequality in the examined distribution, quantifying it in relation to the comparative distribution (equal distribution). Rohde [2008] established a relationship between Theil's inequality measure and the Lorenz curve, thus providing a useful link between these two popular tools for studying inequality. This was achieved by showing that Theil's index can be expressed in terms of the derivatives of the Lorenz curve.

Assuming that $\mathbf{y}=\left\{y_{1}, y_{2}, \ldots, y_{n}\right\}$ is the distribution of income and interpreting the $n$ possible events as $n$ people in the population, we will accept that the share of person $i$ in total income is equal to $s_{i}=\frac{y_{i}}{\sum_{i=1}^{n} y_{i}}=\frac{y_{i}}{n \bar{y}}$. Probabilities $p_{i}$ in formula (1) are interpreted as shares $s_{i}$. In the uniform distribution, the income of the $i$-th person is equal to the average of income, and thus shares $s_{i}=\frac{1}{n}$ for $i=1, \ldots, n$. With this in mind, Theil's inequality measure may be expressed as:

$$
\begin{gathered}
\mathrm{T}=H\left(Y_{e}\right)-H(Y)=\sum_{i=1}^{n} \frac{1}{n} \ln n-\sum_{i=1}^{n} s_{i} \ln \frac{1}{s_{i}}=\sum_{i=1}^{n}\left(s_{i} \ln s_{i}-\frac{1}{n} \ln \frac{1}{n}\right)= \\
=\sum_{i=1}^{n}\left(\frac{y_{i}}{n \bar{y}} \ln \frac{y_{i}}{n \bar{y}}-\frac{1}{n} \ln \frac{1}{n}\right)=\sum_{i=1}^{n}\left(\frac{y_{i}}{n \bar{y}}\left[\ln \frac{y_{i}}{\bar{y}}+\ln \frac{1}{n}\left(1-\frac{\bar{y}}{y_{i}}\right)\right]\right)= \\
=\sum_{i=1}^{n}\left(\frac{y_{i}}{n \bar{y}} \ln \frac{y_{i}}{\bar{y}}+\ln \frac{1}{n}\left[\frac{y_{i}}{n \bar{y}}-\frac{1}{n}\right]\right)=\sum_{i=1}^{n} \frac{y_{i}}{n \bar{y}} \ln \frac{y_{i}}{\bar{y}}+\frac{1}{n} \ln \frac{1}{n} \sum_{i=1}^{n}\left(\frac{y_{i}}{\bar{y}}-1\right)= \\
=\frac{1}{n} \sum_{i=1}^{n} \frac{y_{i}}{\bar{y}} \ln \frac{y_{i}}{\bar{y}} \cdot 1
\end{gathered}
$$

Theil's measure represents a special case of the Generalised Entropy (GE) type measure. The concept of GE measures is based on a comparison of the observed income distribution with the reference distribution. The distance concept implicit in these measures has been developed in the literature [Shorrocks 1984; Jenkins, O’Higgins 1989; Magdalou, Nock 2011]. Divergence measures are used to assess

$$
1 \sum_{i=1}^{n}\left(\frac{y_{i}}{\bar{y}}-1\right)=0
$$


the degree of dissimilarity between two income distributions. The application of the measures characterized in this paper is to consider that the reference distribution is equally distributed for all the individuals, for example, the mean income for all. To put it another way, the divergence measure becomes in this case the traditional inequality index: the more distant the actual income distribution from the situation where all the persons have the mean income, the larger the divergence.

It is required that the distance measure should be additively decomposable by population subgroup. For any two distributions of income $\mathbf{v}=\left\{v_{1}, v_{2}, \ldots, v_{n}\right\}$ and $\mathbf{w}=\left\{w_{1}, w_{2}, \ldots, w_{n}\right\}$ the class of divergence measures can be written as [Jenkins, O’Higgins 1989]:

$$
\begin{gathered}
\mathrm{J}_{\alpha}(\mathbf{v}, \mathbf{w})=\frac{1}{n \alpha(1-\alpha)} \sum_{i=1}^{n}\left[\left(\frac{v_{i}}{\bar{v}}\right)^{\alpha}\left(\frac{w_{i}}{\bar{w}}\right)^{1-\alpha}-1\right], \alpha \neq 0,1, \\
\mathrm{~J}_{1}(\mathbf{v}, \mathbf{w})=\frac{1}{n} \sum_{i=1}^{n}\left(\frac{v_{i}}{\bar{v}}\right) \ln \left(\frac{v_{i}}{\bar{v}} \cdot \frac{\bar{w}}{w_{i}}\right), \\
\mathrm{J}_{0}(\mathbf{v}, \mathbf{w})=\frac{1}{n} \sum_{i=1}^{n}\left(\frac{w_{i}}{\bar{w}}\right) \ln \left(\frac{\bar{v}}{v_{i}} \cdot \frac{w_{i}}{\bar{w}}\right) .
\end{gathered}
$$

The described divergence measures propose to evaluate the shape of an income distribution $\mathbf{v}$, in comparison with the shape of a reference distribution $\mathbf{w}$. The relative measures identified by Cowell [1985] and described by formula (3) are Csiszár's divergences (f-divergences) independently introduced by Csiszár [1963] and Ali and Silvey [1966]. Cowell [1985] characterizes a large class of divergence measures, called measures of distributional change. Moreover, Magdalou and Nock [2011] used Bregman's divergences to the comparison of the observed income distribution with the reference distribution. Csiszár's divergences and Bregman's divergences are distinct but coincide in one specific case: the Kullback-Leibler divergence belongs to both divergence classes. Interestingly, the idea of economic distance or directed distance, was largely investigated in the inequality literature [Shorrocks 1982; Cowell 1985; Magdalou, Nock 2011].

Substituting $\mathbf{y}=\left\{y_{1}, y_{2}, \ldots, y_{n}\right\}$ for $\mathbf{v}=\left\{v_{1}, v_{2}, \ldots, v_{n}\right\}$ and the reference (equal) distribution for $\mathbf{w}=\left\{w_{1}, w_{2}, \ldots, w_{n}\right\}$ formula (3) reduces to:

$$
G E(\alpha)=\frac{1}{n\left(\alpha^{2}-\alpha\right)} \sum_{i=1}^{n}\left[\left(\frac{y_{i}}{\bar{y}}\right)^{\alpha}-1\right],
$$

where $y_{i}$ is the equivalised disposable income of an individual $i, \bar{y}$ is the population mean income, $\alpha \in(-\infty,+\infty)$ and $n$ is the number of individuals in the population. Formula (6) describes the Generalised Entropy (GE) class of inequality indices. The parameter $\alpha$ indexes the members of the class and summarises the sensitivity of $G E(\alpha)$ to income differences in different parts of the income distribution. For $\alpha$ large and positive $G E(\alpha)$ is sensitive to changes in the distribution that affect the upper 
tail; with $\alpha$ small and positive the measure will be more sensitive to what happens at the bottom tail of the income distribution. If $\alpha$ is negative the index is sensitive to changes in the distribution that affect the lower tail [Cowell 2005]. However, in empirical analysis, values of parameter $\alpha$ are typically limited to [-1,2] because otherwise the estimates may be unduly influenced by a small number of very small incomes or very high incomes [Jenkins 2009].

In expression (6) the denominator $n\left(\alpha^{2}-\alpha\right)$ is equal to zero for $\alpha=0$ and $\alpha=1$. De l'Hopital's rule yields appropriate limiting for $\alpha=0$ and $\alpha=1-G E(0)$ is the mean logarithmic deviation $\mathrm{L}=G E(0)=-\frac{1}{n} \sum_{i=1}^{n} \ln \left(\frac{y_{i}}{\bar{y}}\right), G E(1)$ is the Theil index described by formula (2). GE(2) is half the square of the coefficient of variation. Measures belonging to the Generalised Entropy family include several indices such as the variance, measures of industrial concentration, and the Atkinson class of inequality indices [Jenkins 2009].

The Generalized Entropy measures are unbounded above for $\alpha \leq 0$ and if $\alpha>0$ and all incomes are positive, the upper bound depends on the size of the population [Lasso de la Vega, Urrutia 2003]. The maximum value of the Theil index is equal to $\ln (n)$.

\section{Decomposition techniques. The axiomatic approach}

There are many ways of measuring inequality, all of which have some intuitive or mathematical aspect. It is believed that the fundamental approach in measuring inequalities is to specify a set of principles or axioms sufficient to determine an inequality measure uniquely [Cowell 2011]. In this part of the article we start with the axiomatic approach and present five key axioms of inequality measures [Bourguignon 1979; Shorrocks 1980; Litchfield 1999; Cowell 2011]:

1. The Pigou-Dalton Transfer Principle. The Pigou-Dalton principle requires that a regressive transfer decreases social welfare. The inequality measure should indicate an increase (decrease) in inequality as a result of regressive (progressive) transfers of income. In other words, an income transfer from a poorer person to a richer person should increase (or at least not decrease) the inequality measure, and a transfer from a richer individual to a poorer individual should decrease (or at least not increase) the inequality measure.

2. Income Scale Independence (or Income Scale Invariance). The inequality measure should be invariant to uniform proportional changes in incomes. This means that if each individual's income changes by the same proportion then inequality should not change. This property is evident in the case of those measures defined with respect to income shares $s_{i}$, because a proportional income change in all incomes leaves the shares unchanged.

3. Principle of Population Replication (or Population-size Independence). The inequality measure should be invariant to replications of the population: merging two identical incomes distributions should not alter the degree of inequality. 
4. Anonymity (or Symmetry). This requires the inequality measure to be independent of any characteristic of individuals other than their income. In other words, the inequality measure takes the same value, if $\mathbf{y}^{\prime}=\left\{y_{1}^{\prime}, y_{2}^{\prime}, \ldots, y_{n}^{\prime}\right\}$ is obtained from $\mathbf{y}=\left\{y_{1}, y_{2}, \ldots, y_{n}\right\}$ by a permutation of incomes.

5. Decomposability. This axiom requires that overall inequality be related to constituent parts of the distribution, such as population subgroups. This property implies that there should be a coherent relationship between inequality in the whole of the population and inequality in its subgroups. The basic idea is to be able to write a formula giving the total inequality as a function of inequality within the subgroup and inequality between subgroups.

Shorrocks [1980] and Cowell [1995] show that any inequality measure that satisfies the Pigou-Dalton transfer principle, income scale independence, principle of population, anonymity and decomposability must belong to the generalized entropy class or its ordinal transformations.

Apart from measurement of inequality, another vital issue is the decomposition of overall inequality into subcomponents or subgroups. Cowell [1999] suggests that the discussion of the basic axioms of inequality measures includes decomposability as one of the fundamental properties that might be considered in the formal approach to income distribution. The decomposition property is very suitable for assessing the contribution of a set of factors (household-specific attributes or income sources) to overall inequality. In other words, decomposition analysis is helpful in pointing out the sources and the structure of inequality and resolves two major types of problem:

- Decomposition by population subgroup. The aim of this decomposition is to separate total inequality in the distribution into a component of inequality between the selected groups, and the remaining within-group inequality. This can be useful in the analysis of the relationship between inequality in the whole population and inequality within and between subgroups categorised by the type of household, household size, region, household members occupation, education and age. Litchfield [1999] points out that two types of decomposition are of interest: firstly, the decomposition of the level of inequality in any one year, i.e. a static decomposition, and secondly, the decomposition of the change in inequality over a period of time, i.e. a dynamic decomposition.

- Decomposition by income source. Total inequality is expressed as the sum of contribution of factors, where each contribution depends on the incomes from a given source of the factor (labour earnings, income from capital, private and public transfers, etc.). Shorrocks [1982] was the first to offer a unified approach to inequality decomposition by income sources, while Kimhi [2011] proposes interpretations of different inequality decomposition rules when inequality is decomposed by income sources.

The exact decomposition procedure depends on the applied measure of inequality. The traditional approach to decomposition is similar to analysis of variance, which decomposes overall variance into two terms [Foster, Shneyerov 1999]. 
There can be at least two ways to conduct decomposition of inequality: additive and non-additive. In the non-additive decomposition instead of a pure breakdown into two components we can find three terms: a within-group component, a betweengroup component, and an interaction term. It is well known that in general the Gini index is not decomposable in the sense of subgroup consistency [Cowell 1999]. Foster and Shneyerov [1999] underline that the failure of the well-known Gini coefficient to have a neat decomposition into within-group and between-group terms accounts for its relatively infrequent use in this type of analysis.

Since our paper focuses on the Generalized Entropy class of measures below, we present the property of the additive decomposition.

An additive decomposable measure is defined by Bourguignon [1979] as a measure that allows the total inequality of a population to be broken down into a weighted average of the inequality existing within subgroups of the population and the inequality existing between them. The Generalized Entropy class of measures was derived specifically for this purpose and can be axiomatically characterized using a property of additive decomposability. Shorrocks [1980] presents a key characteristic of this class as the only differentiable measures with such a (weighted) additive decomposition, where weights can be general functions of the subgroup means and population sizes. Moreover, Shorrocks [1980; 1984] shows that GE measures (or their positive multiples) are, in fact, the only continuous, normalized, relative measures that satisfy additive decomposability.

Formally, the additive decomposable measure $I(\mathbf{y})$ is defined as follows [Shorrocks 1984]:

$$
I(\mathbf{y})=I\left(\mathbf{y}_{1}, \ldots, \mathbf{y}_{\mathbf{G}}\right)=\sum_{\mathbf{j}=1}^{\mathrm{G}} w_{\mathbf{j}} \cdot I\left(\mathbf{y}_{\mathbf{j}}\right)+I_{B}\left(\mathbf{y}_{\mathbf{1}}, \ldots, \mathbf{y}_{\mathbf{G}}\right),
$$

where $\mathbf{y}_{1}, \ldots, \mathbf{y}_{\mathrm{G}}$ represents any partition of the distribution $\mathbf{y}$ into $\mathrm{G}$ subgroups. When the decomposition is additive, the coefficients $w_{j}\left(\sum_{j=1}^{G} w_{j}=1\right)$ and the betweengroup term $I_{B}\left(\mathbf{y}_{1}, \ldots, \mathbf{y}_{G}\right)$ depend only on subgroup means and population sizes. The first sum in the expression (7) is within-group component and describes a part of overall inequality that is due to inequality within subgroups. The within-group term is a weighted average of group inequalities where the weights depend on the population and income shares. The traditional approach to decomposition uses the arithmetic mean or the geometric mean as the representative income in constructing weights for the within-group term. In contrast, Blackorby, Donaldson and Auersperg [1981] use a generalized mean or q-order mean in decompositions of welfarebased indices. Foster and Shneyerov [1999] extend the standard axiom of additive decomposability to allow the use of any given q-order mean as representative income in the decomposition formula.

The second term $I_{B}\left(\mathbf{y}_{1}, \ldots, \mathbf{y}_{\mathbf{G}}\right)$ is between-group component and measures the extent of inequality due to differences in the group mean income. The between- 
group term represents the level of inequality that would be observed if the income of each person is replaced by the mean income of the respective subgroup.

In particular, total inequality can be written as the sum of the inequality within groups $G E_{W}(\alpha)$ and the inequality between groups $G E_{B}(\alpha)$, where the first is the weighted sum of the inequalities within each subgroup:

$$
G E(\alpha)=G E_{W}(\alpha)+G E_{B}(\alpha) .
$$

The GE measures are decomposed as follows [Elbers et al. 2008]:

$$
\begin{gathered}
G E(\alpha)=\sum_{j=1}^{G} G E_{j}(\alpha) g_{j}\left(\frac{\overline{y_{J}}}{\bar{y}}\right)^{\alpha}+\frac{1}{\alpha^{2}-\alpha}\left[\sum_{j=1}^{G} g_{j}\left(\frac{\overline{y_{J}}}{\bar{y}}\right)^{\alpha}-1\right], \text { for } \alpha \neq 0,1, \\
G E(0)=\sum_{j=1}^{G} G E_{j}(0) g_{j}+\left[\sum_{j=1}^{G} g_{j} \ln \left(\frac{\bar{y}}{\overline{y_{j}}}\right)\right] \\
G E(1)=\sum_{j=1}^{G} G E_{j}(1) g_{j}\left(\frac{\overline{y_{J}}}{\bar{y}}\right)+\sum_{j=1}^{G} g_{j}\left(\frac{\overline{y_{J}}}{\bar{y}}\right) \ln \left(\frac{\overline{y_{J}}}{\bar{y}}\right)
\end{gathered}
$$

where $j$ refers to the sub-group, the $G E_{j}$ refers to the inequality in the sub-group $j$ and $g_{j}$ refers to the population share of the sub-group $j$.

\section{Empirical analysis}

As stated in the introduction, the aim of the paper is two-fold. In addition to the presentation of GE measures and the discussion of their properties, specifically the decomposition property, the empirical aim of the study is to assess the level of income inequality in Poland and to indicate its main determinants. In order to attain this aim we used microdata obtained from the European Union Statistics on Income and Living Conditions (EU-SILC). The data covered information about incomes attained by individual members of the household in 2016. The measures of income inequality were estimated based on the equivalised household disposable income per household member with the use of personal cross-sectional weights.

Our study is based on the assumption that the inequality in a population split into groups, distinguished on the household characteristics, arises from the unequal distribution of income at two levels: the first is the unequal distribution of total income 'between' the groups, and the second is the unequal distribution of income 'within' each group. Five factors are chosen as the possible drivers of income inequality, namely: the type of the household, the size of the household, the labour market status and the educational level of the household head, and the region of residence of the household. 


\subsection{The level of income inequality in Poland}

In the first step of our study we focused on the following question: what is the level of income inequalities for Polish households? In order to assess the inequality of income distribution, we calculated the GE measures for $\alpha=-1,0,1,2$. Following Jenkins' suggestions (2009), we limited our estimation to values of parameter $\alpha \geq-1$ and $\alpha \leq 2$ in order to avoid the measures to be influenced by a small number of very small incomes or very high incomes.

Depending on parameter $\alpha \in(-\infty,+\infty)$ GE measures are sensitive to income differences in different parts of the income distribution, therefore we used $G E(-1)$ and $G E(2)$ respectively to assess inequalities in the group of the poorest households and in the group of the richest ones. The assessment of the overall inequality of income distribution was based on GE measures for $\alpha=0$ and $\alpha=1$. The results are presented below.

Table 1. The GE indices for incomes before and after social transfers

\begin{tabular}{|l|c|c|c|c|}
\hline \multicolumn{1}{|c|}{ Income } & $\mathrm{GE}(-1)$ & $\mathrm{GE}(0)$ & $\mathrm{GE}(1)$ & $\mathrm{GE}(2)$ \\
\hline Before social transfers & 0.6260 & 0.2015 & 0.1746 & 0.2047 \\
\hline After social transfers & 0.2419 & 0.1573 & 0.1509 & 0.1810 \\
\hline
\end{tabular}

Source: own calculations.

The GE indices do not have an upper limit for $\alpha \leq 0$, and if $\alpha>0$ and all incomes are positive, the upper bound depends on the size of the population [Lasso de la Vega, Urrutia 2003]. With this in mind, the level of overall income inequality in Poland can be considered moderate especially in cases of incomes after transfers. As expected, the highest income inequalities occur in the bottom tail of the distribution (before and after transfers respectively $G E(-1)=0.6260, G E(-1)=0.2419$ ). Also, in the upper tail the substantial income dispersion can be observed, however, it is not as strong as in the lower part of the distribution (before transfers $G E(2)=0.2047$; after $G E(2)=0.1810$ ). The differences between the value of the indices for incomes before and after transfers depict the influence of the social system. It is worth noting that under the influence of social transfers, the high values of $G E(-1)$ have decreased the most. This demonstrates how important is the role social transfers play in the poorest households.

In the next step we examined how different household characteristics affect income inequalities. In order to evaluate their impact we decomposed the GE measures, which allowed us to have a better understanding of factors determining inequality.

The between-group component can be conventionally interpreted as income inequality between groups distinguished on household characteristics, which constitute the total inequality. In this way the nature of the causes of income inequality 
is ascribed. The importance of a characteristic in explaining income inequality is denoted as a ratio of the inequality between subgroups to overall inequality.

\subsection{Decomposition by the region of residence}

The starting point in the analysis of the relationship between income inequality and household characteristics was the location of the household. In the economic literature, the uneven social and economic development of individual regions is widely discussed. Intuitively, economic inequality among provinces within a country may serve as the driving force of income inequality because the uneven progress in development made across provinces leads to the diversification of income and worsening income inequality.

In our study we analysed income inequality in six regions distinguished on the NUTS1 level, namely: Central, South, Eastern, North West, South West and North. Table 2 presents the share of population and share of household income in each subgroup separated on that basis, as well as the average incomes (in euros per year).

Table 2. Population share and household income share of subgroups distinguished on the basis of region of residence

\begin{tabular}{|l|c|c|c|c|}
\hline \multicolumn{1}{|c|}{ Region } & Population share & Mean & Relative mean & Income share \\
\hline Central & 0.2071 & 7412.34 & 1.11 & 0.2302 \\
\hline South & 0.2063 & 6815.94 & 1.02 & 0.2109 \\
\hline Eastern & 0.1751 & 5657.73 & 0.85 & 0.1485 \\
\hline Northwest & 0.1602 & 6681.31 & 1.00 & 0.1605 \\
\hline Southwest & 0.1000 & 7089.29 & 1.06 & 0.1063 \\
\hline North & 0.1514 & 6332.17 & 0.95 & 0.1437 \\
\hline
\end{tabular}

Source: own calculations.

As can be seen, the most populated regions are the Central and Southern Regions, almost $42 \%$ of households live in these two regions. Households located in these areas have at their disposal $44 \%$ of total income. On average, household income in the richest, i.e. the Central Region, is $11 \%$ higher than the incomes of households in the Northwest Region, where the average income is close to the national mean. It is worth noting that the structure of incomes in these regions and the structure of population are comparable, income shares are close to population shares. Only the poorest region (the Eastern Region) with an average income at the level of $85 \%$ of the national mean, covering almost $18 \%$ of households have at their disposal about $15 \%$ of total income.

Income inequalities in the regions (Table 3 ) do not differ significantly from the level of inequality for Poland. We noticed that the values of GE measures (for $\alpha=0,1,2)$ are higher in the Central Region meaning that within this subgroup the 
income variability is more pronounced. As expected, in all regions the highest income inequalities can be observed in the lower tail of distribution, i.e. among the poorest households.

Table 3. GE measures for subgroups distinguished based on the region of residence

\begin{tabular}{|l|c|c|c|c|}
\hline \multicolumn{1}{|c|}{ Region } & GE(-1) & GE(0) & GE(1) & GE(2) \\
\hline Central & 0.2269 & 0.1725 & 0.1741 & 0.2184 \\
\hline South & 0.2450 & 0.1496 & 0.1336 & 0.1464 \\
\hline Eastern & 0.2523 & 0.1534 & 0.1381 & 0.1518 \\
\hline Northwest & 0.2058 & 0.1415 & 0.1402 & 0.1771 \\
\hline Southwest & 0.3311 & 0.1643 & 0.1592 & 0.1914 \\
\hline North & 0.1887 & 0.1377 & 0.1315 & 0.1508 \\
\hline
\end{tabular}

Source: own calculations.

Table 4. Decomposition of GE measures by the region of residence

\begin{tabular}{|l|c|c|c|c|c|c|c|c|}
\hline \multicolumn{1}{|c|}{ Region } & $\mathrm{GE}(-1)$ & Contribution & $\mathrm{GE}(0)$ & Contribution & $\mathrm{GE}(1)$ & Contribution & $\mathrm{GE}(2)$ & Contribution \\
\hline Overall & 0.2419 & $100.0 \%$ & 0.1573 & $100.0 \%$ & 0.1509 & $100.0 \%$ & 0.1810 & $100.0 \%$ \\
\hline $\begin{array}{l}\text { Within- } \\
\text {-Group }\end{array}$ & 0.2380 & $98.4 \%$ & 0.1534 & $97.5 \%$ & 0.1471 & $97.5 \%$ & 0.1772 & $97.9 \%$ \\
\hline $\begin{array}{l}\text { Between } \\
\text { Group }\end{array}$ & 0.0040 & $1.6 \%$ & 0.0039 & $2.5 \%$ & 0.0038 & $2.5 \%$ & 0.0037 & $2.1 \%$ \\
\hline
\end{tabular}

Source: own calculations.

The results of the decomposition (Table 4) show that only about $1.6-2.5 \%$ of the income inequality can be explained by the location of the household, whilst more than $97 \%$ of inequality arises from income variability within groups. Therefore we conclude that in Poland, contrary to common opinion, region of residence is not a characteristic that contributes to income inequality formation between households.

Household composition may be another potential source of income inequality. To verify this hypothesis we analysed two characteristics of the household: its size and type of the household.

\subsection{Decomposition by the size of the household}

Since household income consists of the income of all its members, it seems obvious that the household size significantly differentiates the level of household income and may be a source of income inequalities. The dataset covers six subgroups separated on the basis of the number of household members, from one to six persons respectively. Households consisting of more than six members were included in the last subgroup. The structure of population and the structure of income, as well as the mean income for groups, are presented in Table 5. 
Table 5. Population share and household income share of subgroups distinguished on the basis of household size

\begin{tabular}{|l|c|c|c|c|}
\hline \multicolumn{1}{|c|}{ Household Size } & Population Share & Mean & Relative Mean & Income Share \\
\hline 1 person & 0.0842 & 5831.33 & 0.87 & 0.0736 \\
\hline 2 persons & 0.1839 & 7677.27 & 1.15 & 0.2117 \\
\hline 3 persons & 0.2141 & 7215.89 & 1.08 & 0.2317 \\
\hline 4 persons & 0.2170 & 6775.54 & 1.02 & 0.2205 \\
\hline 5 persons & 0.1435 & 6233.55 & 0.93 & 0.1341 \\
\hline 6 and more persons & 0.1572 & 5445.57 & 0.82 & 0.1284 \\
\hline
\end{tabular}

Source: own calculations.

Two subgroups form the largest part of the population, namely three and fourperson households. Their share in the structure of households is $21.4 \%$ and $21.7 \%$, respectively. The smallest group constitutes single-person households, whose share is only $8.4 \%$ of the population. Three and four-person households jointly account for over $45 \%$ of total income, and their average income is higher than the average in Poland by $8 \%$ and $2 \%$, respectively. The highest average income is achieved by two-person households (115\% of the average), while the lowest income is observed in households made up of one and six or more people ( $87 \%$ and $82 \%$ of the average, respectively).

Table 6. GE measures for subgroups distinguished on the basis of household size

\begin{tabular}{|l|l|l|l|l|}
\hline \multicolumn{1}{|c|}{ Household Size } & GE(-1) & GE(0) & GE(1) & GE(2) \\
\hline 1 person & 0.3374 & 0.1846 & 0.1848 & 0.2410 \\
\hline 2 persons & 0.2384 & 0.1722 & 0.1755 & 0.2293 \\
\hline 3 persons & 0.2016 & 0.1368 & 0.1243 & 0.1327 \\
\hline 4 persons & 0.3201 & 0.1625 & 0.1443 & 0.1575 \\
\hline 5 persons & 0.1755 & 0.1407 & 0.1412 & 0.1801 \\
\hline 6 and more persons & 0.1521 & 0.1185 & 0.1093 & 0.1143 \\
\hline
\end{tabular}

Source: own calculations.

When analysing how the size of the household affects income inequality, we noticed that the higher the number of household members the smaller the level of income inequality (Table 6). Our observation is congruent with Redmond's conclusions, i.e. that the broader the definition of household, the more measured inequality tends to decrease, since the dispersion of individual incomes is abated by their aggregation and supposedly egalitarian distribution among all members of the unit [Redmond 1998]. 
Table 7. Decomposition of GE measures by the size of household

\begin{tabular}{|l|c|c|c|c|c|c|c|c|}
\hline $\begin{array}{c}\text { Household } \\
\text { Size }\end{array}$ & $\mathrm{GE}(-1)$ & Contribution & $\mathrm{GE}(0)$ & Contribution & $\mathrm{GE}(1)$ & Contribution & $\mathrm{GE}(2)$ & Contribution \\
\hline Overall & 0.2419 & $100.0 \%$ & 0.1573 & $100.0 \%$ & 0.1509 & $100.0 \%$ & 0.1810 & $100.0 \%$ \\
\hline $\begin{array}{l}\text { Within- } \\
\text {-Group }\end{array}$ & 0.2351 & $97.2 \%$ & 0.1506 & $95.7 \%$ & 0.1443 & $95.7 \%$ & 0.1745 & $96.4 \%$ \\
\hline $\begin{array}{l}\text { Between } \\
\text { Group }\end{array}$ & 0.0069 & $2.8 \%$ & 0.0067 & $4.3 \%$ & 0.0066 & $4.3 \%$ & 0.0065 & $3.6 \%$ \\
\hline
\end{tabular}

Source: own calculations.

In order to assess the contribution of the differences in income between the separated subgroups, the GE measures were decomposed. Based on the results (Table 7), we can state than only slightly more than $4 \%$ of the overall inequality can be attributed to the differences in the size of the households, and $96 \%$ is the effect of income variability within groups.

\subsection{Decomposition by the type of the household}

In order to assess the relationship between income inequalities and types of households we split the households into seven non-overlapping subgroups, namely:

- a one-person household (H-5)2,

- households without dependent children (H-6, H-7 and H-8),

- a single parent household (H-9),

- two adults with one dependent child (H10),

- two adults with two dependent children (H11),

- two adults with three or more dependent children (H12),

- other households with dependent children (H-13 and H-16).

We decided to aggregate some household types distinguished by Eurostat for two reasons. Firstly, the between-group component depends on the differences among subgroups in mean incomes, the relative size of subgroups and the number of subgroups. To ensure its comparability we tried to keep a similar number of subgroups in each decomposition. Secondly, we wanted the presence of dependent children in the household to be a key issue in this decomposition. In our opinion, their presence in the household has an substantial influence on the level and differentiation of household incomes. The structure of the population and the structure of income as well as the mean income for subgroups can be found in Table 8 .

The structure of types of households in Poland is atypical (non-standard) due to the economic situation. The relatively low standard of living as well as the housing shortages force many Polish families to share their dwelling with their relatives. A large number of households is composed of multigenerational families, especially

\footnotetext{
${ }^{2}$ Household types are labelled according to the EU-SILC methodology.
} 
Table 8. Population share and household income share of subgroups distinguished based on household type

\begin{tabular}{|l|c|c|c|c|}
\hline \multicolumn{1}{|c|}{ Household Type } & Population Share & Mean & Relative Mean & Income Share \\
\hline H-5 & 0.0842 & 5831.33 & 0.87 & 0.0736 \\
\hline H-6, H-7, H-8 & 0.3363 & 7396.02 & 1.11 & 0.3730 \\
\hline H-9 & 0.0156 & 5172.97 & 0.78 & 0.0121 \\
\hline H-10 & 0.1082 & 7402.31 & 1.11 & 0.1201 \\
\hline H-11 & 0.1118 & 7057.72 & 1.06 & 0.1183 \\
\hline H-12 & 0.0460 & 5792.37 & 0.87 & 0.0400 \\
\hline H-13, H-16 & 0.2979 & 5887.24 & 0.88 & 0.2629 \\
\hline
\end{tabular}

Source: own calculations.

in the following two subgroups: 'households without dependent children' and 'other households with dependent children'. For that reason, these subgroups have the largest share in the population of households, i.e. $34 \%$ and $30 \%$ respectively. While in the case of the first of these groups its share of income is proportional to the share in households population, the share of the second group in total income is lower by about 4 percentage points than its share in the population.

Single parent households constitute the smallest subgroup, with a share amounting to $1.5 \%$. They also form the poorest group with a mean income at the level of $78 \%$ of the national average. Households of two adults with one dependent child are the richest. Their mean income is $11 \%$ higher than the average in the whole country.

Table 9. GE measures for subgroups distinguished on the basis of household type

\begin{tabular}{|l|c|c|c|c|}
\hline \multicolumn{1}{|c|}{ Household type } & $\mathrm{GE}(-1)$ & $\mathrm{GE}(0)$ & $\mathrm{GE}(1)$ & $\mathrm{GE}(2)$ \\
\hline H-5 & 0.3374 & 0.1846 & 0.1848 & 0.2410 \\
\hline H-6, H-7, H-8 & 0.1922 & 0.1398 & 0.1392 & 0.1733 \\
\hline H-9 & 0.1969 & 0.1532 & 0.1544 & 0.1839 \\
\hline H-10 & 0.2050 & 0.1440 & 0.1320 & 0.1418 \\
\hline H-11 & 0.4953 & 0.2023 & 0.1719 & 0.1883 \\
\hline H-12 & 0.2858 & 0.2328 & 0.2557 & 0.3930 \\
\hline H-13, H-16 & 0.1575 & 0.1240 & 0.1167 & 0.1274 \\
\hline
\end{tabular}

Source: own calculations.

When analysing how the type of the household affects income inequality, we concentrate on the presence of the children in the households, which means that we focused on the following subgroups: H-9, H-10, H-11 and H-12. The GE measures for the above mentioned groups as well as for the other separated subgroups are contained in Table 9. 
When comparing the indices for households with dependent children, we noticed the relationship between the number of children and inequality is opposite to the relationship between the number of household members and inequality. The higher the number of dependent children, the higher the level of income inequality. It is also worth noting that in the poorest subgroup, i.e. single parent households, the values of GE measures are relatively low due to low income variability within the group.

Table 10. Decomposition of GE measures by the type of household

\begin{tabular}{|l|c|c|c|c|c|c|c|c|}
\hline $\begin{array}{c}\text { Household } \\
\text { Type }\end{array}$ & GE(-1) & Contribution & GE $(0)$ & Contribution & GE $(1)$ & Contribution & GE(2) & Contribution \\
\hline Overall & 0.2419 & $100.0 \%$ & 0.1573 & $100.0 \%$ & 0.1509 & $100.0 \%$ & 0.1810 & $100.0 \%$ \\
\hline $\begin{array}{l}\text { Within- } \\
\text {-Group }\end{array}$ & 0.2353 & $97.3 \%$ & 0.1508 & $95.9 \%$ & 0.1445 & $95.7 \%$ & 0.1746 & $96.5 \%$ \\
\hline $\begin{array}{l}\text { Between } \\
\text { Group }\end{array}$ & 0.0066 & $2.7 \%$ & 0.0065 & $4.1 \%$ & 0.0064 & $4.2 \%$ & 0.0063 & $3.5 \%$ \\
\hline
\end{tabular}

Source: own calculations.

The results of the decomposition by household type (Table 10) are comparable to the results of the previous decomposition by household size. Similarly, the differences in income between subgroups distinguished on the household type account for about $4 \%$ of total inequality, and $96 \%$ result from income variability within groups.

\subsection{Decomposition by the labour market status of the household head}

According to the EU-SILC methodology, the head of the household is a person whose income constitutes the prevailing source of household income. In our study, we assumed that the status on the labour market of the household head, determining the main source of household income, may be a potential factor accounting for income inequality. Based on the analysis of the sources of household head's income we recognised the following groups of household:

- employees,

- the self-employed,

- the unemployed,

- retirees living on old-age benefits,

- pensioners living on survivor's and sickness benefits,

- persons living on disability benefits.

Table 11 presents the structure of population and the structure of income as well as the mean income for the groups distinguished.

Undoubtedly, the labour market status of the household head is influential for the household income level. The mean income of households headed by employees exceeds by $20 \%$ that of a household headed by a retiree, and by $34 \%$ that of a household headed by a pensioner and is more than twice higher than that of those 
Table 11. Population share and household income share of subgroups distinguished based on the labour market status of the household head

\begin{tabular}{|l|c|c|c|c|}
\hline \multicolumn{1}{|c|}{ Labour market status } & Population share & Mean & Relative mean & Income share \\
\hline Employees & 0.6573 & 7211.80 & 1.08 & 0.7108 \\
\hline The self-employed & 0.1205 & 6026.94 & 0.90 & 0.1089 \\
\hline The unemployed & 0.0026 & 5018.58 & 0.75 & 0.0019 \\
\hline Retirees living on old-age benefits & 0.1811 & 5766.35 & 0.86 & 0.1566 \\
\hline $\begin{array}{l}\text { Pensioners living on survivor's and } \\
\text { sickness benefits }\end{array}$ & 0.0172 & 4738.70 & 0.71 & 0.0122 \\
\hline Persons living on disability benefits & 0.0213 & 3003.32 & 0.45 & 0.0096 \\
\hline
\end{tabular}

Source: own calculations.

living on disability benefits. Households that are headed by a self-employed person receive on average only $90 \%$ of the income of a similar household headed by an employee. However, it should be remembered that the subgroup of the self-employed contains not only business owners, but also craftsmen and individual farmers.

Table 12. GE measures for subgroups distinguished based on the labour market status of the household head

\begin{tabular}{|l|c|c|c|c|}
\hline \multicolumn{1}{|c|}{ Labour market status } & $\mathrm{GE}(-1)$ & $\mathrm{GE}(0)$ & $\mathrm{GE}(1)$ & $\mathrm{GE}(2)$ \\
\hline Employees & 0.2175 & 0.1494 & 0.1483 & 0.1820 \\
\hline The self-employed & 0.4511 & 0.2002 & 0.1582 & 0.1592 \\
\hline The unemployed & 0.5466 & 0.4237 & 0.4346 & 0.5803 \\
\hline Retirees living on old-age benefits & 0.1221 & 0.1038 & 0.1005 & 0.1092 \\
\hline $\begin{array}{l}\text { Pensioners living on survivor's and } \\
\text { sickness benefits }\end{array}$ & 0.1103 & 0.0930 & 0.0888 & 0.0938 \\
\hline Persons living on disability benefits & 0.1404 & 0.1252 & 0.1245 & 0.1382 \\
\hline
\end{tabular}

Source: own calculations.

When analysing the GE indices for separated subgroups (Table 12), we noticed that the level of inequality among employees is close to the level of total inequality in our country, while in the remaining subgroups the differences are more significant. As with overall inequality, the differences in income in this subgroup are slightly higher in both tails of the distribution. The GE measures for household headed by the self-employed are higher than total inequality, especially in the lower distribution tail, and their values indicate that the diversity of income decreases with increasing income. Income inequality in households living on old-age benefits, survivor's and sickness benefits, and disability benefits are low due to the low variability of incomes in each subgroup. The lesser variation in these groups of households results from the similar amounts of those social benefits. The highest inequality, resulting 
from the strong diversity of incomes, seems to be natural for a household headed by an unemployed person.

Table 13. Decomposition of GE measures by the labour market status of the household head

\begin{tabular}{|l|c|c|c|c|c|c|c|c|}
\hline $\begin{array}{c}\text { Labour } \\
\text { market } \\
\text { status }\end{array}$ & GE(-1) & Contribution & GE(0) & Contribution & GE(1) & Contribution & GE(2) & Contribution \\
\hline Overall & 0.2419 & $100.0 \%$ & 0.1573 & $100.0 \%$ & 0.1509 & $100.0 \%$ & 0.1810 & $100.0 \%$ \\
\hline $\begin{array}{l}\text { Within- } \\
\text {-group }\end{array}$ & 0.2291 & $94.7 \%$ & 0.1465 & $93.1 \%$ & 0.1415 & $93.8 \%$ & 0.1725 & $95.4 \%$ \\
\hline $\begin{array}{l}\text { Between } \\
\text { group }\end{array}$ & 0.0128 & $5.3 \%$ & 0.0108 & $6.8 \%$ & 0.0094 & $6.2 \%$ & 0.0084 & $4.7 \%$ \\
\hline
\end{tabular}

Source: own calculations.

The results of the decomposition of GE measures are presented in Table 13. They show that more than $6 \%$ of the income inequality can be explained by the labour market status of the household head. This is the highest contribution of an intergroup component in overall inequality so far, therefore we conclude that in Poland the labour market status of breadwinner is a characteristic that contributes to income inequality formation between households.

\subsection{Decomposition by the level of education of the household head}

The level of education of household members can be another potential driver of income inequality. It is believed that income inequality is based on differences in human capital, which is related to individuals' education and experience. Education affects household members' superior skills and productivity, which ultimately increases household income.

Although the EU-SILC methodology in the scope of education of household members is based on the International Standard Classification of Education (ISCED 2011), which includes nine categories for educational attainment, in the dataset from 2016 respondents were classified on highest educational attainment only into six levels: less than primary, primary, lower secondary, upper secondary, post-secondary non-tertiary, and tertiary.

In our study, when dividing households into subgroups distinguished based on the level of education of the head of the household, we followed the EUSILC classification. Since almost $12 \%$ of respondents did not declare their level of education, we created one additional group, covering their incomes, and we labelled it as 'undeclared'. Table 14 presents the share of population and the share of household income in each subgroup separated on that basis, the level of education of the household head as well as the average incomes in each subgroup. 
Table 14. Population share and household income share of subgroups distinguished based on the level of education of the household head

\begin{tabular}{|l|c|c|c|c|}
\hline \multicolumn{1}{|c|}{ Education } & Population share & Mean & Relative mean & Income share \\
\hline Less than primary & 0.0055 & 4412.81 & 0.66 & 0.0036 \\
\hline Primary & 0.0914 & 4315.40 & 0.65 & 0.0591 \\
\hline Lower secondary & 0.0057 & 4753.48 & 0.71 & 0.0041 \\
\hline Upper secondary & 0.5120 & 5827.21 & 0.87 & 0.4474 \\
\hline Post-secondary & 0.0247 & 6808.78 & 1.02 & 0.0252 \\
\hline Tertiary & 0.2376 & 9552.78 & 1.43 & 0.3403 \\
\hline Undeclared & 0.1232 & 6515.72 & 0.98 & 0.1203 \\
\hline
\end{tabular}

Source: own calculations.

The diversification of income among the subgroups distinguished based on the level of education of the household head is significant. As expected, there is a positive correlation between the level of education of the household head and the level of household income. On average, a household headed by a person with tertiary education has more than twice as much income as a household headed by a person with primary or less than primary education. The income gap between 'the best educated subgroup' and the others decreases as the educational level increases.

Table 15. GE measures for subgroups distinguished on the basis of the educational level of the household head

\begin{tabular}{|l|c|c|c|c|}
\hline \multicolumn{1}{|c|}{ Education } & $\mathrm{GE}(-1)$ & $\mathrm{GE}(0)$ & $\mathrm{GE}(1)$ & $\mathrm{GE}(2)$ \\
\hline Less than primary & 0.0889 & 0.0782 & 0.0798 & 0.0885 \\
\hline Primary & 0.1680 & 0.1244 & 0.1156 & 0.1238 \\
\hline Lower secondary & 0.0923 & 0.0828 & 0.0800 & 0.0829 \\
\hline Upper secondary & 0.2060 & 0.1270 & 0.1136 & 0.1203 \\
\hline Post-secondary & 0.6384 & 0.1427 & 0.1242 & 0.1475 \\
\hline Tertiary & 0.1743 & 0.1314 & 0.1328 & 0.1618 \\
\hline Undeclared & 0.1735 & 0.1230 & 0.1107 & 0.1151 \\
\hline
\end{tabular}

Source: own calculations.

When analysing the GE measures for the subgroups distinguished based on the level of education (Table 15), the first thing that can be observed is the very low level of income inequality in two subgroups: in households headed by a person with a level of education less than the primary and in households headed by a person with a lower secondary education. In our opinion, there are two reasons for this. Firstly, the population share and the income share of these subgroups are only about $0.5 \%$. Secondly, each of the subgroups seems to be strongly homogenous. Since in Poland 
primary education is compulsory, the subgroup of households headed by a person with a lower level of education covers mostly older people living on social benefits or people unable to study. The level of lower secondary education was introduced in Poland in 1999. Households headed by a person with a lower secondary education consist mainly of people younger than 30 , with rather low wages. The homogeneity of groups and low variation of incomes are, in our opinion, the reason for the low intragroup inequality in these subgroups. In other subgroups, i.e. in households headed by a person with primary, upper secondary and tertiary education, the level of income inequality is lower than the level of overall inequality in our country. The only exception is the subgroup with a post-secondary educated household head, where the incomes among the poorest are strongly differentiated.

Table 16. Decomposition of GE measures by the educational level of the household head

\begin{tabular}{|l|c|c|c|c|c|c|c|c|}
\hline \multicolumn{1}{|c|}{ Education } & $\mathrm{GE}(-1)$ & Contribution & $\mathrm{GE}(0)$ & Contribution & $\mathrm{GE}(1)$ & Contribution & $\mathrm{GE}(2)$ & Contribution \\
\hline Overall & 0.2419 & $100.0 \%$ & 0.1573 & $100.0 \%$ & 0.1509 & $100.0 \%$ & 0.1810 & $100.0 \%$ \\
\hline Within-group & 0.2121 & $87.7 \%$ & 0.1272 & $80.9 \%$ & 0.1199 & $79.5 \%$ & 0.1484 & $82.0 \%$ \\
\hline $\begin{array}{l}\text { Between } \\
\text { group }\end{array}$ & 0.0298 & $12.3 \%$ & 0.0301 & $19.1 \%$ & 0.0310 & $20.5 \%$ & 0.0326 & $18.0 \%$ \\
\hline
\end{tabular}

Source: own calculations.

As can be seen in Table 16, among the five analysed factors, income inequality across education levels contributes most significantly to income inequality in Poland. Specifically, the decomposition by levels of the highest educational attainment yields the result that the between-group component constitutes approximately $20 \%$ of income inequality, which means that income inequality would decrease by about $20 \%$ if everyone in the society had the same level of education.

\section{Conclusion}

Based on the results of our analysis, we can state that the characteristics related to human capital are the most influential factors of income variability between households, where $20 \%$ of the total income inequality between households can be assigned to differences in the level of education that describe the formal side of human capital. The labour market status of the breadwinner, related to the real value of human capital, contributes to the overall level of inequality to a smaller extent than education (about $7 \%$ of the total income inequality). In spite of this it still remains the second driving factor of income inequality in Poland.

The characteristics describing the composition of the household, namely the size and the type of the household, are less significant as each of them explains only about $4 \%$ of the overall income inequality. Since the results showed that no more than $2.5 \%$ of income inequality can be explained by the place of residence of the 
household, the contribution of this characteristic to the total income inequality seems to be negligible.

The results of the current analysis are congruent with our previous research [Muszyńska, Wędrowska 2018] as well as with the results of other authors [Paulus 2004; Medgyesi 2014; Militaru, Stanila 2015]. All these studies regarding the causes of income inequality confirmed that in the post-transition countries the most important sources of income inequality are related to human capital, and above all to the level of education.

The empirical aim of the study was achieved due to the application of Generalized Entropy measures. As was indicated in the paper, the Generalized Entropy class of measures was derived specifically for the fulfilment of an additive decomposition property, and what is more, they are the only measures that satisfy this property. At the same time the relationship between these measures and the measures of divergence was emphasised.

What we were seeking to do while presenting the GE measures and discussing their properties, especially the property of additive decomposition, was to recover these measures for practical work. We hope that this paper will convince the readers that GE measures can be a useful tool for the study of inequality among populations and population subgroups.

\section{Acknowledgment}

This paper is prepared within the research project: Income and inequality of income of European households - RPP 162/2018-EU-SILC and is based on data derived from Eurostat, EU Statistics on Income and Living Conditions - EU-SILC CROSSSECTIONAL UDB 2016 - the version of October 2017. The responsibility for all the conclusions drawn from the data lies entirely with the authors.

\section{Bibliography}

Ali S., Silvey S., 1966, A general class of coefficients of divergence of one distribution from another, Journal of the Royal Statistical Society B, vol. 28, pp. 131-142.

Blackorby C., Donaldson D., Auersperg M., 1981, A new procedure for the measurement of inequality within and among population subgroups, Canadian Journal of Economics, vol. 14, pp. 665-685.

Bourguignon F., 1979, Decomposable income inequality measures, Econometrica, 47(4), pp. 901-920.

Csiszár I., 1963, Eine inrofmationtheoretische Ungleichung und ihre Anwendung auf den Beweis der Ergodizit"at von Markotschen ketten, Publ. Math. Inst. Hungar. Acad. Sci., 8, pp. 85-108.

Cowell F.A., 1980, On the structure of additive inequality measures, Review on Economic Studies, 47, pp. 521-531.

Cowell F.A., 1985, Measures of distributional change: an axiomatic approach, Review on Economic Studies, 52, pp. 135-151.

Cowell F.A., 1995, Measuring Inequality (2nd edition), Harvester Wheatsheaf, Hemel Hempstead.

Cowell F.A., 1999, Measurement of Inequality, [in:] Atkinson A.B., Bourguignon F. (eds.), Handbook of Income Distribution, North Holland, Amsterdam. 
Cowell F.A., 2005, Theil, Inequality Indices and Decomposition, ECINEQ Working Paper 2005-1, London.

Cowell F.A., 2011, Measuring Inequality (3rd edition), London School of Economics, Perspectives in Economic Analysis, Oxford.

Cowell F.A., Kuga K., 1981, Additivity and the entropy concept: an axiomatic approach to inequality measurement, Journal of Economic Theory, 25(1), pp. 131-143.

Elbers C., Lanjouw P., Mistiaen J.A., Özler B., 2008, Reinterpreting between-group inequality, The Journal of Economic Inequality, 6(3), pp. 231-245.

Foster J.E., Shneyerov A.A., 1999, A general class of additively decomposable inequality measures, Economic Theory 14, pp. 89-111.

Jenkins S.P., 2009, Distributionally-sensitive inequality indices and the GB2 income distribution, Review of Income and Wealth, 55(2), pp. 392-398.

Jenkins S.P., O'Higgins M., 1989, Inequality measurement using 'norm incomes': were Garvy and Paglin onto something after all?, Review of Income and Wealth, no. 3, pp. 265-282.

Kimhi A., 2011, Comment: on the interpretation (and misinterpretation) of inequality decompositions by income sources, World Development, vol. 39, no. 10, pp. 1888-1890.

Lasso de la Vega M.C., Urrutia A.M., 2003, A new factorial decomposition for the Atkinson measure, Economics Bulletin, vol. 4, no. 29, pp. 1-12.

Lesne A., 2014, Shannon Entropy: A rigorous notion at the crossroads between probability, information theory, dynamical systems and statistical physics, Mathematical Structures in Computer Science, vol. 24(3), pp. 240-311.

Litchfield J.A., 1999, Inequality: Methods and Tools, Text for the World Bank's Website on Inequality, Poverty and Socio-Economic Performance.

Magdalou B., Nock R., 2011, Income distributions and decomposable divergence measures, Journal of Economic Theory, 146(6), pp. 2440-2454.

Medgyesi M., 2014, Components of income inequality and its change in EU countries, 2004-2010. ImPRovE Discussion Paper no. 14/01. Antwerp.

Militaru E., Stanila L., 2015, Income variability in Romania: decomposing income inequality by household characteristics, Procedia Economics and Finance, 26, pp. 227-233

Muszyńska J., Wędrowska E., 2018, Income Inequality in the Visegrad Group Countries. Decomposition of Generalized Entropy Measures - a paper presented at the 12th International Days of Statistics and Economics in Prague.

Paulus A., 2004, Income Inequality and its Decomposition: the Case of Estonia, [in:] Modelling the Economies of the Baltic Sea Region, vol. 17, pp. 206-235.

Przybyszewski R., Wędrowska E., 2005, Algorytmiczna teoria entropii, Przegląd Statystyczny, nr 2, t. 52, Warszawa, s. 85-102.

Redmond G., 1998, Households, Families and the Distribution of Income, Social Policy Research Centre Newsletter, 71(1), 1, pp. 4-5.

Rohde N., 2008, Lorenz curves and generalised entropy inequality measures, Modeling Income Distributions and Lorenz Curves, Springer, pp. 271-283.

Shorrocks A.F., 1980, The class of additively decomposable inequality measures, Econometrica, 48(3), pp. 613-625.

Shorrocks A.F., 1982, Inequality decomposition by factor components, Econometrica, 50(1), pp. 193-211.

Shorrocks A.F., 1984, Inequality decomposition by population subgroups, Econometrica, 52(6), pp. 1369-1385.

Theil H., 1967, Economics and Information Theory, North Holland, Amsterdam. 


\section{NIERÓWNOŚCI DOCHODOWE GOSPODARSTW DOMOWYCH W POLSCE: DEKOMPOZYCJA MIAR UOGÓLNIONEJ ENTROPII}

Streszczenie: W artykule skupiono uwagę na miarach uogólnionej entropii. Celem teoretycznym artykułu jest prezentacja własności zastosowanych miar, ze szczególnym uwzględnieniem własności addytywnej dekompozycji. Cel empiryczny stanowi ocena poziomu nierówności dochodów w Polsce i wskazanie ich głównych determinant. W analizie empirycznej wykorzystano mikrodane pozyskane z badania EU-SILC. Na podstawie wyników stwierdzono, że cechy związane z kapitałem ludzkim są najbardziej wpływowymi czynnikami zmienności dochodów między gospodarstwami domowymi. Natomiast cechy charakteryzujące skład gospodarstwa domowego w mniejszym stopniu przyczyniają się do ogólnego poziomu nierówności.

Słowa kluczowe: nierówności dochodowe, miary uogólnionej entropii, dekompozycja. 